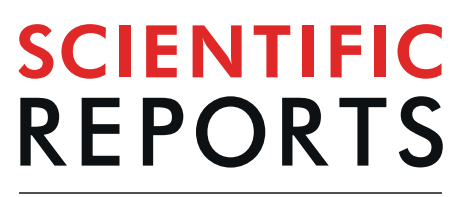

natureresearch

\title{
Antioxidant Activities of an Exopolysaccharide (DeinoPol) Produced by the Extreme Radiation-Resistant Bacterium Deinococcus radiodurans
}

\author{
Shun Mei Lin $\mathbb{D}^{1,2}$, Chan Yu Baek ${ }^{1,2,3}$, Jong-Hyun Jung ${ }^{1,4}$, Woo Sik Kim ${ }^{1}$, Ha-Yeon Song ${ }^{1}$, \\ Ji Hee Lee ${ }^{1}$, Hyun Jung Ji ${ }^{1}$, Yong Z Zii ${ }^{1,4}$, Bo Sun Kang ${ }^{5}$, Yong-Sun Bahn ${ }^{3}$, Ho Seong Seo ${ }^{1,4^{*}}$ \& \\ Sangyong Lim $\mathbb{1}^{1,4^{*}}$
}

Deinococcus radiodurans shows extreme resistance to a range of remarkable environmental stresses. Deinococcal exopolysaccharide (DeinoPol) is a component of the cell wall, but its role in stress resistance has not yet been well-described. In this study, we isolated and characterized DeinoPol from Deinococcus radiodurans R1 strain and investigated its application as an antioxidant agent. Bioinformatic analysis indicated that dra0033, encoding an ExoP-like protein, was involved in DeinoPol biosynthesis, and dra0033 mutation significantly decreased survival rates in response to stresses. Purified DeinoPol consists of different monosaccharides and has a molecular weight of approximately 80 to $100 \mathrm{kDa}$. DeinoPol also demonstrates highly protective effects on human keratinocytes in response to stress-induced apoptosis by effectively scavenging ROS. Taken together, these findings indicate that DeinoPol is the first reported deinococcal exopolysaccharide that might be used in cosmetics and pharmaceuticals as a safe and attractive radical scavenger.

Exposure to ultraviolet (UV) radiation can generate reactive oxygen species (ROS), resulting in DNA, lipid, and protein damage in cells and tissues such as the skin ${ }^{1}$, which becomes mildly inflamed, leading to photo-aging and carcinogenesis $^{2,3}$. The ROS and free radicals that are generated tend to stabilize themselves by scavenging electrons from biomolecules, triggering the activation of many cellular signaling cascades, including apoptosis and necrosis ${ }^{4}$. A broad spectrum of natural antioxidants such as flavonoids, polyphenols, and sterols may be deployed to lessen these effects ${ }^{5,6,7}$. Given their low negative effect on organisms and the environment, natural products with photo-protective properties are increasingly used to prevent radiation-induced skin damage.

Recent research has shown that polysaccharides from natural products possess wide-ranging beneficial therapeutic effects and health-promoting properties ${ }^{8}$. Bacterial exopolysaccharides (EPSs) are mostly nontoxic natural biopolymers with extensive applications in areas such as pharmaceuticals, nutraceuticals and functional foods, cosmetics, and insecticides ${ }^{9-13}$. An extreme resistance to ionizing radiation, desiccation, UV radiation, oxidizing agents, and electrophilic mutagens has been observed in Deinococcus radiodurans ${ }^{14}$. This is attributed to an enhancement of functional redundancies in both efficient protection from ROS by protein and lipid modifications and in DNA repair mechanisms ${ }^{15}$. These characteristics are of interest in developing it for bioremediation of radioactive wastes and biomolecule production. The deinococcal cell envelope consists of a fragile, soft layer containing carotenoids, lipids, proteins, and $\mathrm{EPSs}^{16,17}$. However, whether it has protective capacities against ROS-induced cellular damage remains poorly understood.

\footnotetext{
${ }^{1}$ Research Division for Radiation Science, Korea Atomic Energy Research Institute, Jeongeup, Republic of Korea. ${ }^{2}$ R\&D Center, MediNResearch, Jeongeup, Republic of Korea. ${ }^{3}$ Department of Biotechnology, College of Life Science and Biotechnology, Yonsei University, Seoul, Republic of Korea. ${ }^{4}$ Department of Radiation Science, University of Science and Technology, Daejeon, Republic of Korea. ${ }^{5}$ Department of Radiological Science, Konyang University, Daejeon, Republic of Korea. *email: hoseongseo@kaeri.re.kr; saylim@kaeri.re.kr
} 
A

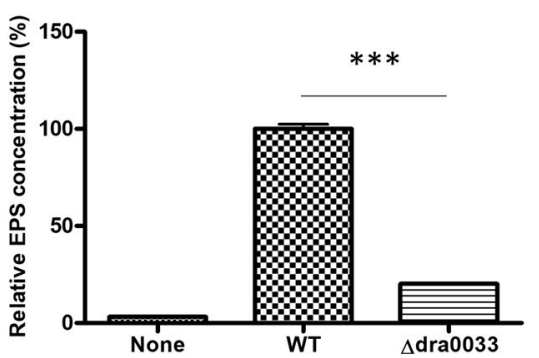

B

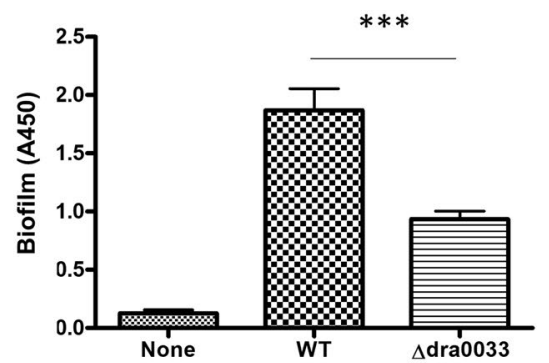

C

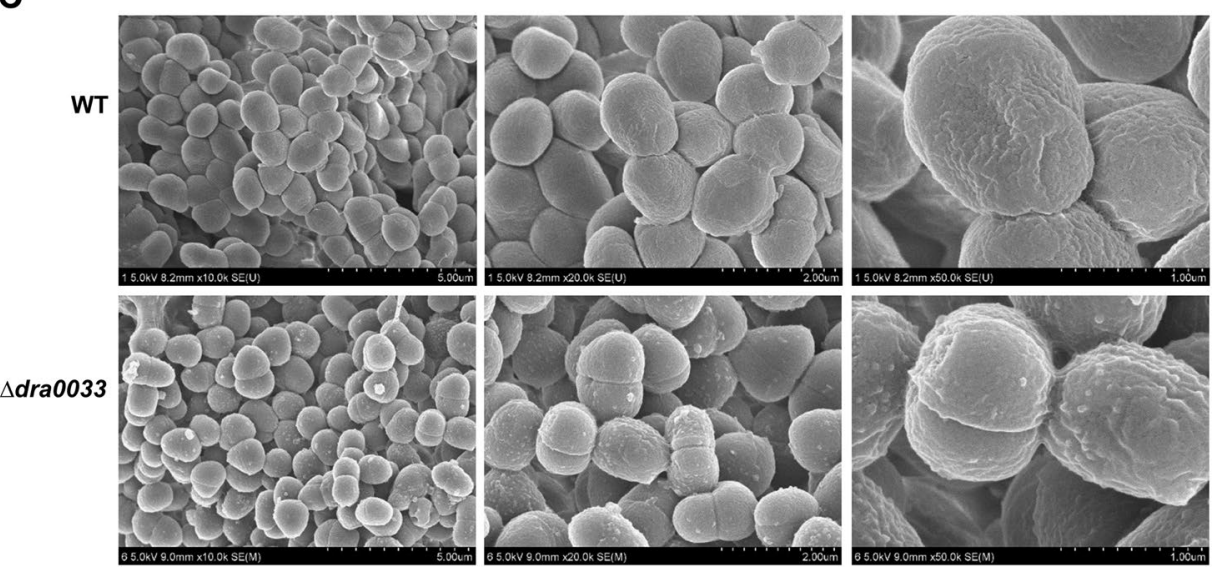

Figure 1. Characterization of DeinoPol production in D. radiodurans R1 and dra0033 mutant. (A) Relative quantification of DeinoPol production in D. radiodurans $\mathrm{R} 1$ and its isogenic mutant ( $\Delta$ dra0033). Deinococcus was cultured in TY broth for $48 \mathrm{~h}$ at $30^{\circ} \mathrm{C}$, and DeinoPol was precipitated with $80 \%$ ethanol at $4{ }^{\circ} \mathrm{C}$. DeinoPol was hydrolyzed and reacted with anthrone and absorbance was read at $490 \mathrm{~nm}$. (B) Relative biofilm formation of $D$. radiodurans $\mathrm{R} 1$ and its isogenic mutant ( $\Delta d$ ra0033). Bacteria were seeded in a 96-well plate and incubated for $48 \mathrm{~h}$ at $30^{\circ} \mathrm{C}$. Biofilm formation was measured by staining with $1 \%$ crystal violet, and absorbance was read at $450 \mathrm{~nm}$. (C) Surface layers of $D$. radiodurans $\mathrm{R} 1$ and its isogenic mutant ( $\Delta d r a 0033)$. Surface-expressed DeinoPol was visualized by scanning electron microscopy (SEM). The rough surface and septa structure indicated a decreased amount of EPS on the deinococcal surface.

The present study aimed to elucidate the role of the deinococcal EPS, DeinoPol in oxidative stress, as well as to characterize its sugar composition and antioxidant effects, including scavenging effects on hydroxyl radicals and anti-apoptosis activities in human keratinocytes.

\section{Results}

Identification and characterization of DeinoPol synthesis genes in D. radiodurans. In previous studies, an ExoP-like protein was shown as a critical regulator of EPS synthesis, directly or indirectly. PSI-BLAST analysis of the predicted amino acid sequence of the ExoP-like protein of Pseudomonas solanacearum indicated that DRA0033 exhibited 95/329 (29\%) amino acid identity ${ }^{18}$. To examine whether dra0033 was involved in EPS synthesis, we first constructed a dra0033-deficient strain in D. radiodurans reference strain $\mathrm{R} 1$ and determined the amount of DeinoPol in the culture supernatants using an ethanol-precipitation method. As shown in Fig. 1A, the mutant produced $79.8 \%$ less DeinoPol than that by the WT strain. Bacterial EPSs enable the attachment and subsequent formation of biofilm of bacteria on surfaces ${ }^{9}$. When WT and $\Delta d r a 0033$ strains were cultured on polystyrene plates for 3 days, the amount of biofilm formation by $\Delta d r a 0033$ was significantly lower compared to that by WT, suggesting that inefficient DeinoPol production through deleting the dra0033 gene led to reduced attachment and propagation of $D$. radiodurans on surfaces and, therefore, reduced biofilm formation (Fig. 1B). We also compared the extracellular structures using scanning electron microscopy (SEM). The WT strain showed a smooth surface and no clear septa structure, indicating that the bacteria were likely surrounded by a layer of EPS, whereas $\Delta d r a 0033$ displayed a rough surface, clear septa, and small rippled-grape skin (Fig. 1C). All these data suggested that Deinococcus produces EPS and DRA0033 is likely to be directly or indirectly involved in DeinoPol synthesis.

Involvement of DeinoPol in stress resistance of $D$. radiodurans. Since EPSs are part of a strategy for surviving adverse stress conditions ${ }^{19,20}$, we compared the survival ability of the WT and $\Delta d r a 0033$ variants in response to external stresses. As shown in Fig. 2A-D, WT strain was extremely resistant to $\gamma$-radiation, $\mathrm{H}_{2} \mathrm{O}_{2}, \mathrm{UV}$ exposure, and desiccation, whereas a reduction of survival ability was observed in the $\Delta d r a 0033$ variant. 
A

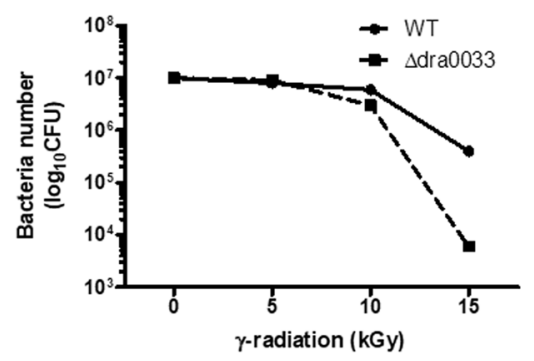

D

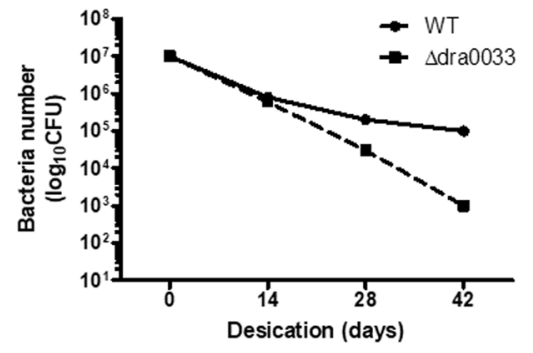

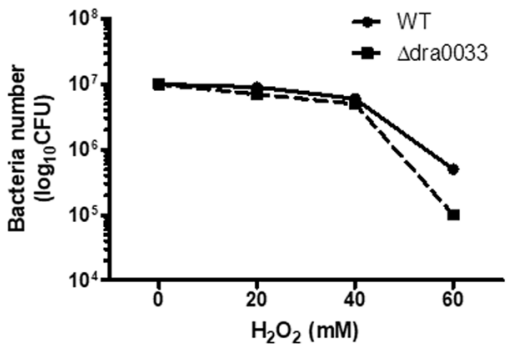

C

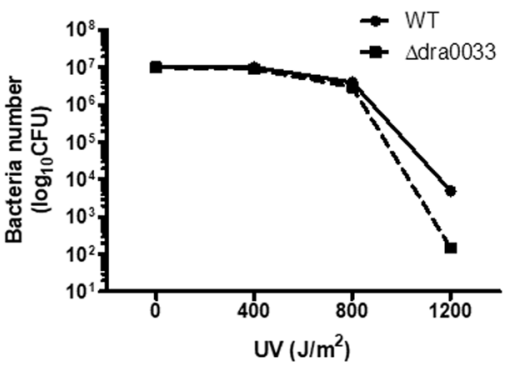

E

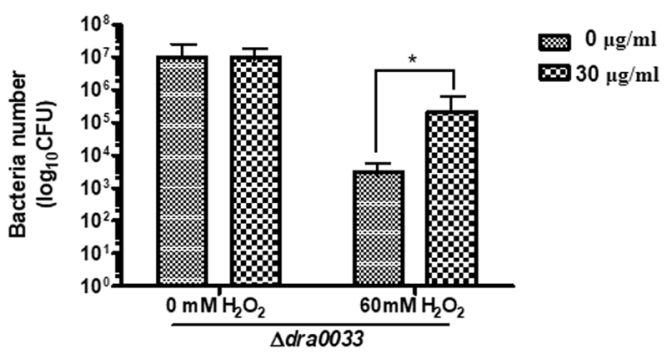

Figure 2. Effect of DeinoPol expression on the resistance of $D$. radiodurans R1. (A-D) Survival curves for $D$. radiodurans $\mathrm{R} 1$ and $\Delta d r a 0033$. Mid- $\log$ phase of $D$. radiodurans $\mathrm{R} 1$ and its isogenic mutant $(\Delta d r a 0033)$ were exposed to $\gamma$-radiation (A), hydrogen peroxide for $1 \mathrm{~h}(\mathbf{B})$, UVC (C) or desiccation (D). Surviving bacteria were calculated by plating on TGY agar plates followed by serial dilution. (E) Enhancement of the survival of $\Delta d r a 0033$ against hydrogen peroxide stress with addition of exogenous purified DeinoPol $(0 \mathrm{or} 30 \mu \mathrm{g} / \mathrm{mL})$. Mid- $\log$ phase $\Delta d r a 0033$ was pretreated with DeinoPol $(30 \mu \mathrm{g} / \mathrm{mL})$ for $30 \mathrm{~min}$ followed by treatment with $60 \mathrm{mM}$ hydrogen peroxide for $1 \mathrm{~h}$. Surviving bacteria were calculated by plating on TGY agar plates followed by serial dilution. Data are mean \pm standard deviation. Asterisks indicate significant difference between $\Delta d r a 0033$ pre-treated with 0 and $30 \mu \mathrm{g} / \mathrm{mL}$ DeinoPol. $* P<0.05$.

To directly investigate the effect of DeinoPol in D. radiodurans $\mathrm{R} 1, \Delta$ dra0033 was pre-treated with purified DeinoPol $(30 \mu \mathrm{g} / \mathrm{mL})$ for $30 \mathrm{~min}$ followed by incubation with a high concentration of $\mathrm{H}_{2} \mathrm{O}_{2}(60 \mathrm{mM})$ for 60 min. The untreated $\Delta d r a 0033$ strain were reduced in number by approximately $3.62 \log$ after $\mathrm{H}_{2} \mathrm{O}_{2}$ treatment, whereas only $1.77 \log$ reduction was observed in DeinoPol pre-treated $\Delta d r a 0033$ (Fig. 2E). These data indicate that DeinoPol production might be required for deinococcal resistance to extreme abiotic stresses.

Biochemical analysis of DeinoPol. To determine the biochemical characteristics of DeinoPol, ethanol precipitation and size-exclusion chromatography were performed on deinococcal culture supernatant, followed by measurement of the eluted polysaccharide with anthrone reaction analysis ${ }^{21}$. As shown in Fig. $3 \mathrm{~A}$, DeinoPol eluted as a $80-100 \mathrm{kDa}$ molecule forming a single, symmetrical peak, indicating that DeinoPol is likely to be homogenous and has relatively lower molecular weight than those of other well-known bacterial EPSs. Eluted DeinoPol contained $89.9 \%$ polysaccharide, $8.8 \%$ protein, and $1.3 \%$ DNA. Protein and DNA concentrations were calculated by measuring the optical density at $280 \mathrm{~nm}$ and $260 \mathrm{~nm}$, respectively.

The major oligosaccharide composition of DeinoPol was analyzed using BIO-LC mass spectrometry ${ }^{19}$. We found six major monosaccharides: xylose, galactose, fucose, glucose, arabinose, and fructose, with molar ratios of 10.6:6.1:4.2:3.8:2.6:1.0 (Fig. 2B). In addition, five unknown sugar peaks were detected, accounting for $14.89 \%$ of the total carbohydrates. No identical or similar oligosaccharide composition of bacterial polysaccharide structure was found in the Bacterial Carbohydrate Structure DataBase (csdb.glcoscience.ru), indicating that this is the first report of DeinoPol as a novel EPS.

Protective effect of DeinoPol against gamma-irradiation. EPSs purified from Bacillus sp. isolated from the desert has high antioxidant activity in vitro ${ }^{20}$. We, therefore, investigated whether $D$. radiodurans affected the survival of $\gamma$-irradiated mice. Mice $(n=5)$ were injected with live WT or $\Delta d r a 0033\left(10^{8} \mathrm{CFU} / \mathrm{mice}\right)$ intraperitoneally (i.p.) and then subjected to $\gamma$-radiation at $10 \mathrm{~Gy}$. Notably, live D. radiodurans showed no severe invasiveness or organ colonization (spleen, liver, kidney) in mice upon inoculation with $10^{8} \mathrm{CFU}$ (Supplementary Fig. 1). All mice inoculated with either PBS or $\Delta d r a 0033$ died at 11 days after irradiation (Fig. $4 \mathrm{~A}$ ), whereas those inoculated with WT strain showed a significantly delayed death, indicating that DeinoPol is likely to provide a protective effect against lethal doses of irradiation.

To evaluate the effect of DeinoPol in radiation-induced cell death, human primary adult keratinocytes (NHEK-Ad) were irradiated at $10 \mathrm{~Gy}$ in the presence of DeinoPol $(10 \mu \mathrm{g})$, and the apoptosis ratio was measured by staining with propidium iodide (PI) and Annexin V (Fig. 4B). When cells were irradiated (panel b), most were located in gates G2 (5.1\%) and G4 (46.0\%), indicating that radiation effectively induced early and late apoptosis. 
A

S300 SEC

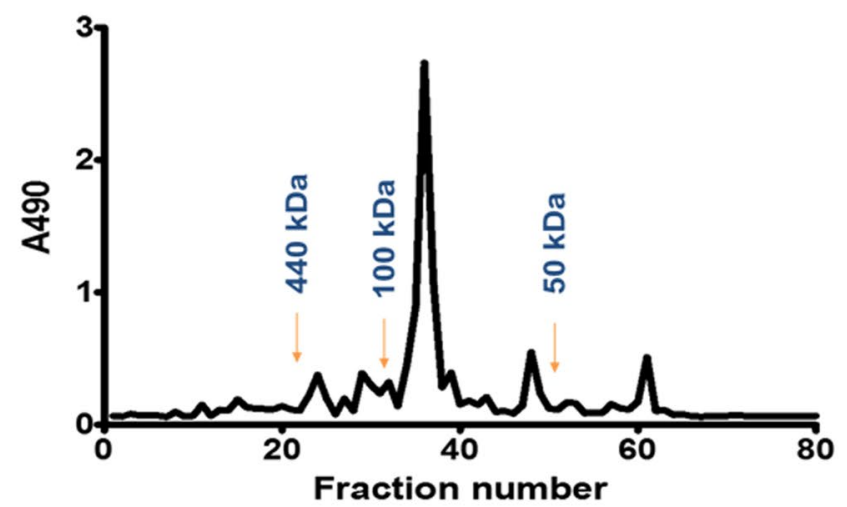

B

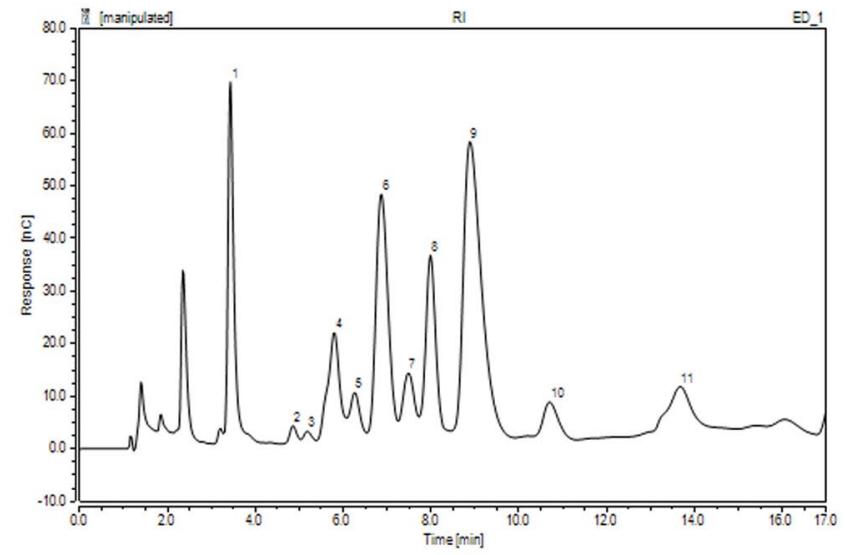

\begin{tabular}{cccccc}
\hline No. & $\begin{array}{c}\text { Ret. Time } \\
\mathrm{min}\end{array}$ & Peak Name & $\begin{array}{c}\text { Height } \\
\mathrm{nC}\end{array}$ & $\begin{array}{c}\text { Area } \\
\mathrm{nC}^{*} \mathrm{~min}\end{array}$ & $\begin{array}{c}\text { Rel.Area } \\
\%\end{array}$ \\
\hline 1 & 3.433 & Fucose & 68.75 & 10.66 & 12.66 \\
2 & 4.85 & - & 3.397 & 0.634 & 0.75 \\
3 & 5.183 & - & 2.26 & 0.485 & 0.58 \\
4 & 5.8 & Arabinose & 21.014 & 6.716 & 7.97 \\
5 & 6.267 & - & 9.404 & 2.668 & 3.17 \\
6 & 6.967 & Galactose & 46.951 & 15.382 & 18.26 \\
7 & 7.483 & - & 12.815 & 4.058 & 4.82 \\
8 & 7.883 & Glucose & 34.92 & 9.537 & 11.32 \\
9 & 8.883 & Xylose & 56.346 & 26.857 & 31.89 \\
10 & 10.7 & Fructose & 6.744 & 2.533 & 3.01 \\
11 & 13.667 & - & 8.148 & 4.695 & 5.57 \\
\hline \hline Total: & & & $\mathbf{2 7 0 . 7 5}$ & $\mathbf{8 4 . 2 2 5}$ & $\mathbf{1 0 0}$ \\
\hline
\end{tabular}

Figure 3. Biochemical characterization of DeinoPol. (A) Gel filtration chromatography of DeinoPol. Purified DeinoPol $(10 \mathrm{mg})$ was fractionated on Sephacryl S-300HR. The $\mathrm{x}$-axis indicates $5 \mathrm{~mL}$ of each fraction. The column was equilibrated with Tris buffer with $0.1 \mathrm{M} \mathrm{NaCl}$ at a flow rate of $0.5 \mathrm{~mL} / \mathrm{min}$. The $\mathrm{y}$-axis indicates the peaks of eluted DeinoPol as measured by anthrone reaction with absorbance read at $490 \mathrm{~nm}$. (B) Sugar profile of DeinoPol by Bio-LC. Ten mg dried DeinoPol was hydrolyzed and analyzed on a CarboPac TM PA1 column with a HPAEC-PAD system. The $\mathrm{x}$ - and $\mathrm{y}$-axis indicate the retention time and integrated response ratio, respectively.

However, irradiated cells pretreated with DeinoPol (panel c) showed significant reduction in the ratio of apoptotic cells (G2 and G4) and increase in the ratio of live cells (77.6\%; G3), which was similar to that of non-irradiated cells [(panel a): 80.2\%], indicating that DeinoPol has the potential to protect cells from death induced by irradiation. Moreover, TUNEL assay was used to evaluate the level of apoptotic DNA fragmentation by radiation induced ROS (Fig. 4C). When cells were irradiated (panel b), fragmented DNA (bright green) was detected inside the cells. In contrast, irradiated cells pretreated with DeinoPol (panel c) showed the reduced green signal which was comparable level with non-irradiated cells (panel a). 
A

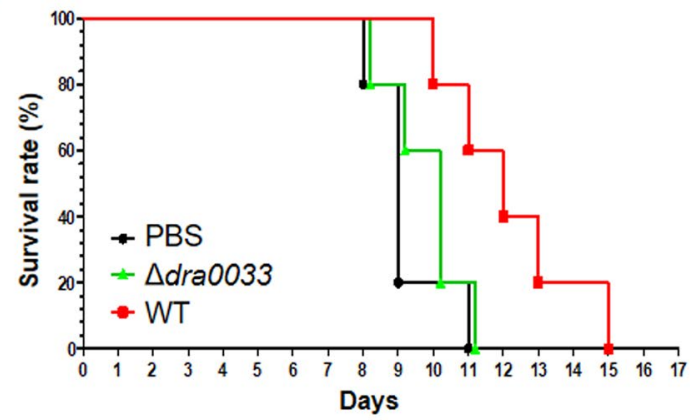

B
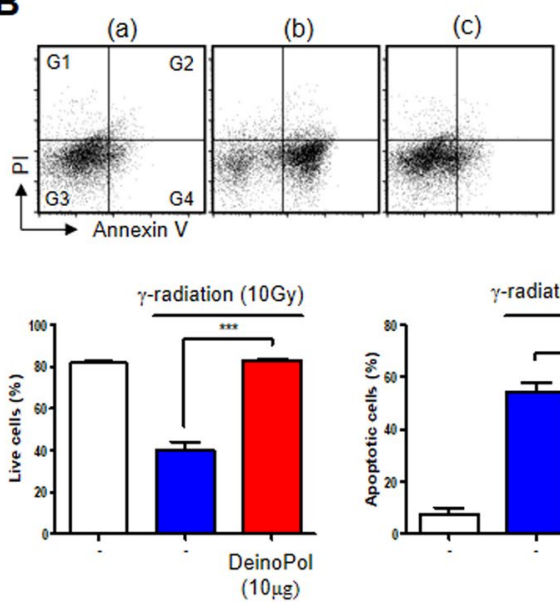

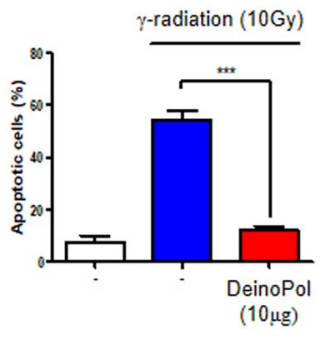

C

(a)

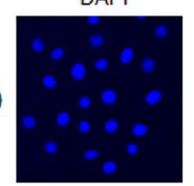

(b)

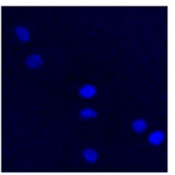

(c)

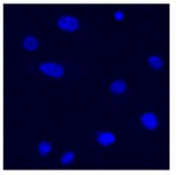

TUNEL
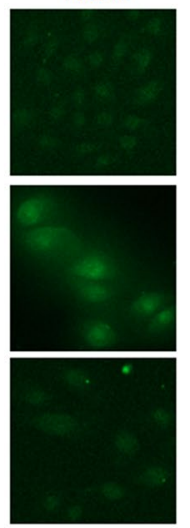

Merge
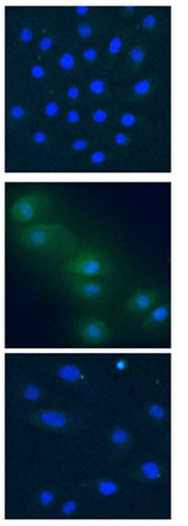

Figure 4. Effect of DeinoPol on $\gamma$-radiation-induced cell death. (A) Mice protected by injection of DeinoPolexpressing WT strain. Mice $(\mathrm{n}=10)$ were injected with $10^{8} \mathrm{CFU}$ of WT or $\Delta d r a 0033$ strain followed by gammairradiation $(10 \mathrm{~Gy})$. Mouse survival was monitored for 17 days. (B) Quantitative analysis of $\gamma$-radiation-induced apoptosis was performed by flow cytometry using NHEK-Ad cells. Cells were treated with medium alone (a), medium with $10 \mathrm{~Gy} \gamma$-radiation (b), or $10 \mu \mathrm{g}$ DeinoPol with $10 \mathrm{~Gy} \gamma$-radiation (c) followed by incubating for $2 \mathrm{~h}$. Cells were then subjected to flow cytometry after Annexin V-FITC/PI staining. Representative Annexin V and PI dot plots of 10,000 total cells. Quadrant 1 (Q1) contained necrotic cells (Annexin V negative and PI positive), Q2 represented the late stages of apoptosis (Annexin V and PI positive), Q3 contained living cells without signs of apoptosis (Annexin V and PI negative), and Q4 showed early stages of apoptosis (Annexin V positive and PI negative). Corresponding living (Q3) and apoptotic cell (Q2 + Q4) populations for each treatment group were analyzed. Data are presented as mean \pm SD of three independent experiments. $* P<0.05$. (C) Effect of DeinoPol on $\gamma$-radiation-induced DNA fragmentation in apoptotic cells. Cells were irradiated with $10 \mathrm{~Gy}$ followed by incubation for $2 \mathrm{~h}$. The TUNEL assay was carried out to assess apoptotic cells after the treatments. Green fluorescent staining indicates positive apoptotic cells, and DAPI (blue) staining was used as a nuclear stain.

Reduction of ROS-induced cell death by treatment with DeinoPol. Next, since ROS such as peroxides, superoxide $\left(\bullet^{\bullet} \mathrm{O}^{-}\right)$, hydroxyl radical $\left({ }^{\bullet} \mathrm{OH}\right)$, singlet oxygen, are significantly increased owing to environmental stress, such as drought, salinity, chilling, nutrient deficiency, metal toxicity and UV radiation ${ }^{22-24}$, we further investigated the role of DeinoPol in minimizing cell damage induced by UV radiation and $\mathrm{H}_{2} \mathrm{O}_{2}$. NHEK-Ad cells were pre-treated with DeinoPol, followed by irradiation with UVB $\left(120 \mathrm{~mJ} / \mathrm{cm}^{2}\right)$. At $12 \mathrm{~h}$ after irradiation, cell viability was analyzed by CCK- 8 assay. In contrast to non-treated cells, pre-treated cells presented a steadily increasing viability until saturation was observed at approximately $3.0 \mu \mathrm{g} / \mathrm{mL}$, similar to that of non-irradiated cells (Fig. 5A). When NHEK-Ad cells were directly sensitized with exogenous $\mathrm{H}_{2} \mathrm{O}_{2}$, cell viability decreased in a dose-dependent manner (Fig. 5B). At $1000 \mu \mathrm{M} \mathrm{H}_{2} \mathrm{O}_{2}$, cell viability was $41.3 \%$ lower than that in untreated cells, but no significant reductions in cell viability were found in DeinoPol $(10 \mu \mathrm{g})$ pre-treated cells. Notably, no cytotoxicity was found in NHEK-Ad cells treated with over $1000 \mu \mathrm{g} / \mathrm{mL}$ of DeinoPol (Supplementary Fig. 2).

Intracellular ROS are one of the most damaging effects of UVB irradiation on the skin, with subsequent damage to cellular components directly, leading to cell death ${ }^{25}$. To examine the potential protective effect of DeinoPol on intracellular ROS generated by UVB irradiation, cells were exposed to UVB $\left(120 \mathrm{~mJ} / \mathrm{cm}^{2}\right)$ in the presence of DeinoPol $(10 \mu \mathrm{g})$, and intracellular ROS level was measured using DCFDA, a probe that becomes fluorescent when oxidized by free radicals. Intracellular fluorescence signal was high in NHEK-Ad cells that did not receive DeinoPol treatment (Fig. 5C). However, ROS content was significantly attenuated in the DeinoPol pre-treated group, similar to that in non-irradiated cells. These results indicate that DeinoPol has potential protective effect for a human keratinocyte cell line (HaCaT) against radiation-induced oxidative stress. 
A

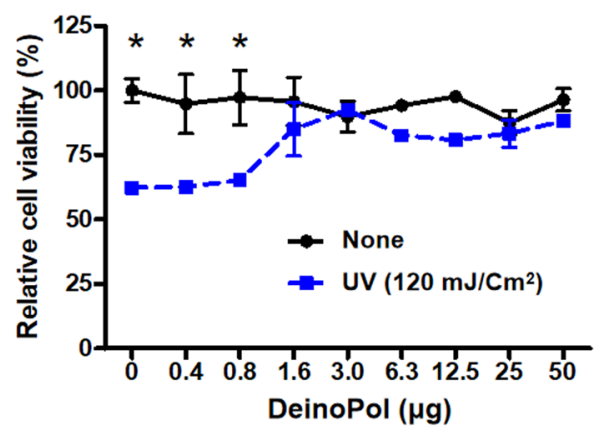

C

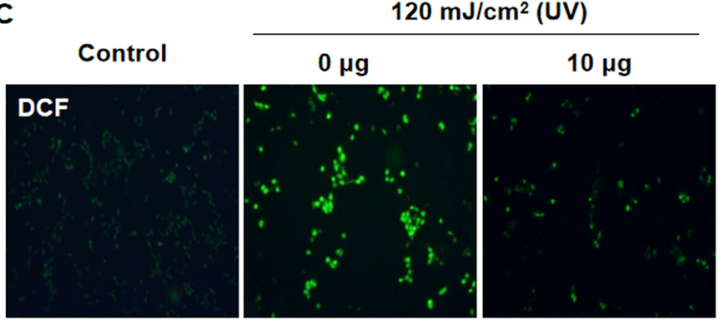

E

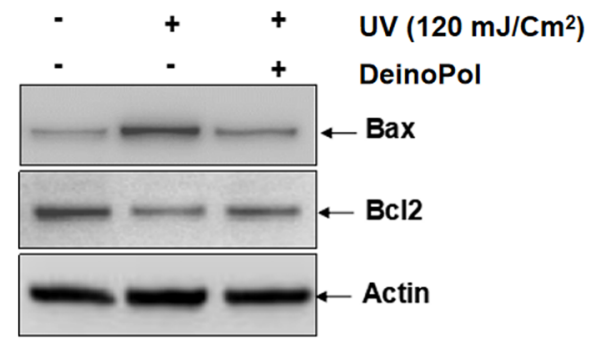

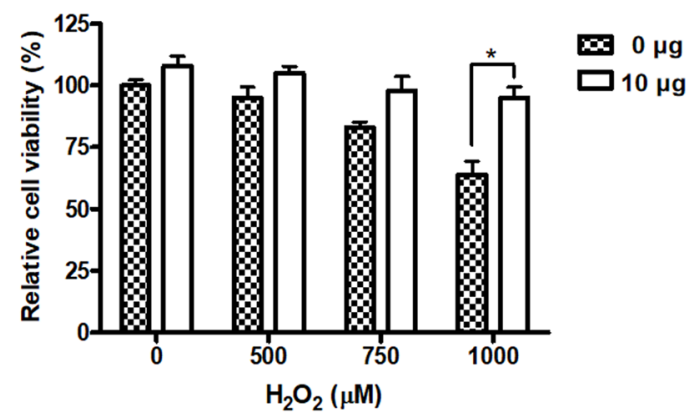

D

D

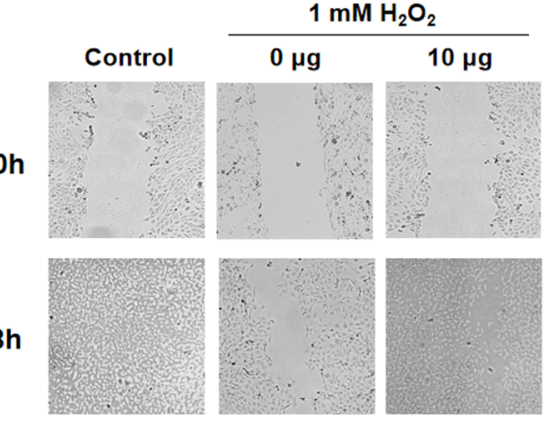

$\mathbf{F}$

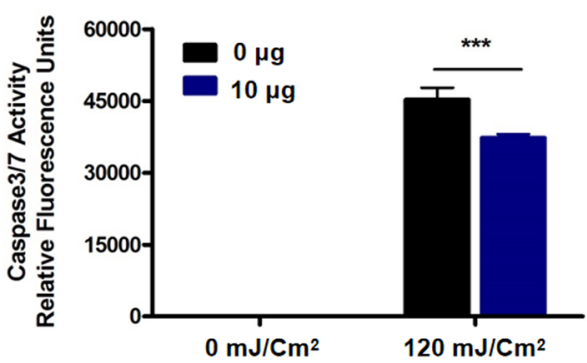

Figure 5. Enhancement of keratinocyte viability and proliferation by DeinoPol. (A,B) Effect of DeinoPol on viability of NHEK-Ad cells. A NHEK-Ad monolayer was pre-treated with the indicated concentration of DeinoPol followed by irradiation with UVB (A) or treatment with hydrogen peroxide (B). (C) ROS-scavenging effect of DeinoPol. NHEK-Ad cells were irradiated with $120 \mathrm{~mJ} / \mathrm{cm}^{2}$ UVB in the presence of $10 \mu \mathrm{g}$ DeinoPol followed by incubation with $5 \mu \mathrm{M}$ H2DCFDA for $2 \mathrm{~h}$. Fluorescence intensity was visualized by fluorescence microscope. (D) Effect of DeinoPol on NHEK-Ad proliferation by scratch wound healing assay. Scratched $\mathrm{HaCaT}$ cells were treated with $10 \mu \mathrm{g}$ DeinoPol and $1 \mathrm{mM}$ hydrogen peroxide. After $18 \mathrm{~h}$ incubation, photos of the scratched monolayer were captured. (E) Bax and Bcl-2 expression of UVB $\left(120 \mathrm{~mJ} / \mathrm{cm}^{2}\right)$-irradiated NHEK-Ad were analyzed in the presence of DeinoPol $(10 \mu \mathrm{g})$ by western blotting. (F) DeinoPol reduced Caspase-3/7 activity induced by UVB. NHEK-Ad cells were treated with DeinoPol $(10 \mu \mathrm{g})$ followed by irradiation with UVB $\left(120 \mathrm{~mJ} / \mathrm{cm}^{2}\right)$. Caspase $3 / 7$ activity was determined by measuring the enzyme kinetics at $2 \mathrm{~h}$. Data are mean \pm standard deviation. $* P<0.05$, $* * P<0.005$, ***P $<0.001$ compared with DeinoPol untreated group.

Another indicator of ROS-induced cell damage is wound repair, since cells irradiated with UV or treated with $\mathrm{H}_{2} \mathrm{O}_{2}$ may be inhibited in migration and proliferation ${ }^{25,26}$. To determine whether pre-treatment with DeinoPol protects cells from damage caused by ROS and further enhances cell proliferation, we performed a wound-healing assay (Fig. 5D). Because of the slow growth of NHEK-Ad, we used keratinocyte cancer cell line (HaCaT) for this experiment. Under normal conditions, the scratched wound of the HaCaT monolayer was completely closed within $18 \mathrm{~h}$, but when cells were treated with $1000 \mu \mathrm{M}$ of $\mathrm{H}_{2} \mathrm{O}_{2}$, the wound was not completely closed until after $18 \mathrm{~h}$, indicating that ROS-induced cell damage caused the reduction of wound healing. However, when cells were treated with $\mathrm{H}_{2} \mathrm{O}_{2}$ in the presence of DeinoPol, the wound area of the cell monolayer closed more than it did in the cells that did not receive DeinoPol pre-treatment. These results indicate that DeinoPol protected cells from ROS-induced damage and led to more efficient cell migration and proliferation.

Inhibition of apoptosis-related signaling pathway by treatment with DeinoPol. UV-induced ROS can lead the depolarization of the mitochondrial membrane, stimulating Bcl2/Bax pro-apoptotic protein 
expression and activating procaspase-3 to cause cell death via apotosis ${ }^{27-29}$. To examine the effect of DeinoPol on UV-induced apoptosis, NHEK-Ad cells were irradiated in the presence of DeinoPol (10 $\mu \mathrm{g})$, and Bax2 and Bax protein expression was then determined (Fig. $5 \mathrm{E}$ ). Bcl2 protein expression in keratinocytes was significantly lower and Bax protein expression was concomitantly higher after $120 \mathrm{~mJ} / \mathrm{cm}^{2} \mathrm{UVB}$ irradiation compared to those in non-irradiated control. In contrast, irradiated cells in the presence of DeinoPol $(10 \mu \mathrm{g})$ showed reduced Bax expression and increased $\mathrm{Bcl} 2$ expression, similar to those in non-irradiated cells. A previous study showed that increasing the $\mathrm{Bax} / \mathrm{Bcl}-2$ ratio up-regulates caspase- 3 to promote cell apoptosis ${ }^{29}$. We next examined caspase $3 / 7$ activity in NHEK-Ad cells under irradiation (Fig. 5F). Without irradiation, the activity of caspase 3/7 was barely detected in NHEK-Ad cells. When cells were irradiated with $120 \mathrm{~mJ} / \mathrm{cm}^{2}$ of UV, caspase $3 / 7$ activity dramatically increased, reaching $45 \mathrm{kU}$, but its activity significantly decreased to $\sim 32 \mathrm{kU}$ when pre-treated with DeinoPol, indicating that DeinoPol can inhibit cell apoptosis via caspase-mediated pathways.

\section{Discussion}

UV radiation induces water radiolysis and produces hydroxyl radicals by the Fenton or Haber-Weiss reaction ${ }^{30,31}$. This oxidative stress causes various cutaneous lesions, such as photoaging and photocarcinogenesis ${ }^{1}$. In addition, chronic exposure to UV radiation damages the integrity of the extracellular matrix in the skin tissues, and this damage is responsible for skin wrinkling, laxity, dryness, and thickness ${ }^{2,3}$. Deinococcus spp. have highly diverse and redundant antioxidant defense systems ${ }^{14,15,32}$. The ROS-scavenging system is composed of several lines of enzymatic and non-enzymatic antioxidants such as catalase, peroxidase, superoxide dismutase, lipoic acid, intracellular manganese, pyrroloquinoline quinone (PQQ), and carotenoids ${ }^{5,9,17,33}$. Bacterial EPSs are involved in various biological functions such as storage of energy, cell wall architecture, cellular communication, molecular organization, and stress resistance ${ }^{9}$. To our knowledge, this is the first study to show that deinococcal EPS, also called DeinoPol, is another type of antioxidant involved in resistance to severe environmental stresses, including UV radiation and hydroxyl radicals.

To date, most industrially important EPSs are produced in plants, animals, or algae, because of the low cost of downstream processing ${ }^{10,34,35}$. However, the use of plant- and animal-derived resources is becoming limited because of environmental disruption, depletion, and contamination. As an alternative, several bacterial EPSs have been reported during recent decades as a source of high-value biomaterials to produce cosmetics, pharmaceuticals, and natural medicines ${ }^{11,36}$. Dextran, discovered in the mid- $19^{\text {th }}$ century, was originally used in solution as a plasma expander ${ }^{9}$. Researchers are now focused on isolating structurally and functionally identical EPSs from bacteria, such as those isolated from extreme environments (deep seas, hot springs, Antarctic areas). These organisms are attractive sources for valuable and identical EPSs; $D$. radiodurans is one such species that produces several valuable molecules, but the structure and function of these molecules have not been reported yet.

Because of the antioxidant effects of DeinoPol, its application in cosmetics and biomedicine is an attractive research area. However, to create a high-value medical polymer, it is crucial to reduce production costs and obtain a high degree of purity without loss of the original functional properties ${ }^{20,37}$. To improve the productivity of DeinoPol, it is crucial to optimize the fermentation process. Bacterial EPS productivity is highly influenced by media components and cultivation conditions, such as carbon source, temperature, and growth phase. Production of GalactoPol and FucoPol isolated from Pseudomonas oleovorans and Enterobacter A47, respectively, are maximized under aerobic conditions, with carbon availability concomitant with nitrogen and oxygen limitation ${ }^{38}$. In contrast, gellan and cellulose production is favored in media supplemented with vitamins and amino acids ${ }^{39-44}$. We also investigated the optimal culture condition for DeinoPol production based on its sugar composition analyzed by Bio-LC mass spectrometry in this study. We examined fucose, galactose, rhamnose, glucose, arabinose, mannose, xylose, and fructose as carbon sources but did not find significant enhancement of DeinoPol production in the media supplemented with different carbon sources (Supplementary Fig. 03). Another strategy to improve EPSs in bacteria is genetic modification of the EPS biosynthesis pathway. When the $d r a 0033$ gene encoding ExoP-like protein was deleted, DeinoPol production was significantly reduced. We observed that overexpression of both $d r 0054$ and $d r 0055$ genes increased DeinoPol production by approximately $60 \%$ (Korea Patent:10-2018-0030335). Further biosynthesis mechanisms of DeinoPol, as well as the influence of DR0054 and DR0055 proteins on DeinoPol production, should be investigated to determine how DeinoPol can be produced in the cosmetic industry.

In addition to enhancing productivity, the required degree of DeinoPol purity is another criterion for its application in biomedical and cosmetic industries. Most bacterial EPSs are purified by cell lysis and precipitation with water-miscible solvents (e.g., methanol, ethanol, or isopropanol) ${ }^{19,39,40}$. We used gradient ethanol precipitation to purify DeinoPol, but its high toxicity $\left(\mathrm{LD}_{50}=12.5 \mu \mathrm{g} / \mathrm{mL}\right)$ presents a limitation for its use as a cosmetic ingredient. We, therefore, used the Sevage method after ethanol precipitation to remove toxic, insoluble materials such as lipids and membrane protein $\mathrm{s}^{41-43}$. The final product was shown to be non-toxic at over $1000 \mu \mathrm{g} / \mathrm{mL}$ in NHEK-Ad (Supplement ary Fig. 2). However, the purity of DeinoPol was likely to be less than $90 \%$ based on gel filtration chromatography and on protein and nucleic acid concentration analyses. To obtain a higher grade of DeinoPol, additional processes should be performed following precipitation and the Sevage method, such as protein removal by protein precipitation with trichloroacetic acid or proteinase treatment ${ }^{42,43}$.

Research interest in bacterial EPSs continues to increase and is focused on isolating new polymers with identical health-associated effects ${ }^{8,45}$. To our knowledge, we are the first to isolate and characterize a deinococcal EPS and report its possible application as an anti-ROS agent. Next, we will further develop the production and purification process to reduce manufacturing costs and enhance purity of the final product, anticipating that new market needs could be created for value-added products in which traditional EPSs are unable to compete. 


\begin{abstract}
Materials and Methods
Mouse experiments. All animal experiments were conducted with the approval of the Committee on The Use and Care of Animals at Korea Atomic Energy Research Institute (KAERI-IACUC-2018-010) and performed according to accepted veterinary standards. Seven-week old female C57BL/6 mice were purchased from Orient Bio (Seongnam, Korea). Mice were intraperitoneally injected with $D$. radiodurans $\mathrm{R} 1$ or its isogenic mutant strain $\left(10^{8} \mathrm{CFU} / \mathrm{mice}\right)$ in PBS. At $3 \mathrm{~h}$ post administration, mice were $\gamma$-irradiated at $13 \mathrm{~Gy}$ using Gammacell ${ }^{\circledR} 40$ Exactor (Best Theratronics Ltd; Ottawa, Canada) at Advanced Radiation Technology Institute, Korea Atomic Energy Research Institute (Jeoneupsi, Korea). Mouse blood, spleen, lungs, and liver were collected 3 days after administration. Tissues were homogenized by plunging in $1.5 \mathrm{ml}$ of PBS through a $40 \mu \mathrm{m}$ mesh strainer, and bacterial numbers were counted. Mice survival and body weight were monitored and recorded daily for 17 days.
\end{abstract}

Bacteria strains and culture conditions. Deinococcus radiodurans R1 (ATCC13939) was obtained from the American Type Culture Collection (ATCC) and cultivated at $30{ }^{\circ} \mathrm{C}$ in TY broth containing $0.5 \%$ tryptone and $0.3 \%$ yeast extract or TGY broth containing $0.5 \%$ tryptone, $0.3 \%$ yeast extract, and $0.1 \%$ glucose ${ }^{31}$. All culture media used in this study was purchased from Difco (Franklin Lakes, NJ, USA).

DRA0033 mutant construction. The DRA0033 mutant strain was constructed using the double cross-over recombination method as previously described ${ }^{46}$. The $1024 \mathrm{bp}$ upstream and $718 \mathrm{bp}$ downstream of $d r a 0033$ were amplified with the primer upstream set (3803:AAG GTA CCG CCC CAA ACA GTT TC and 5803:TTC TCG AGA ACG CTC CAG TTC GG) and downstream set (3804:AAG GAT CCG CCG CGC TCA GGG CTC and 5804:TTG CAT GCA GCG CGG GGT TAT C) and cloned into the pKatCAT plasmid. The cloned plasmid was transferred into D. radiodurans $\mathrm{R} 1$ as previously described ${ }^{46}$, and chloramphenicol-resistant transformants were selected on TGY agar plates. Gene replacement was confirmed by diagnostic PCR using primers (3805:TGT GGG TCT GGA CAC GGG CG and 4805:AGG AAC AAA CCA ACA ACA GA) that bind outside the mutant cassette on the genomic DNA of $D$. radiodurans $\mathrm{R} 1$.

DeinoPol purification. DeinoPol was extracted, isolated, and purified as described in previous studies ${ }^{39-42}$ with slight modifications. D. radiodurans R1 strain was cultured in $4 \mathrm{~L}$ of TGY broth at $30^{\circ} \mathrm{C}$, shaking at $900 \mathrm{rpm}$. After $48 \mathrm{~h}$ of incubation, the culture was mixed with $0.1 \%$ deoxycholate to lyse the bacterial cell wall and heated at $100^{\circ} \mathrm{C}$ for $10 \mathrm{~min}$ to inactivate the bacteria and enzymes. Then, the cells were removed by centrifugation at $10,000 \times g$ for $30 \mathrm{~min}$ at $4^{\circ} \mathrm{C}$. The supernatant was concentrated and dialyzed using a Minimate tangential flow filtration system with $30 \mathrm{~K}$ Minimate capsule (Pall Life Sciences; Port Washington, NY, USA). The concentrated supernatant (approximately $40 \mathrm{~mL}$ ) was precipitated with $160 \mathrm{~mL}$ of $95 \%$ ethanol (Daejungchem; Seoul, Korea) at $4{ }^{\circ} \mathrm{C}$ for $12 \mathrm{~h}$, and the precipitate was collected by centrifugation at $5000 \times g$ for $10 \mathrm{~min}$ at $4{ }^{\circ} \mathrm{C}$ to yield the crude polysaccharide solution. The proteins in the crude polysaccharide were removed by the Sevage method as described previously ${ }^{41,42}$. Briefly, the precipitate was dissolved in $10 \mathrm{~mL}$ of distilled water and mixed with $30 \mathrm{~mL}$ chloroform: $n$-butanol $(4: 1 \mathrm{v} / \mathrm{v})$. After shaking vigorously for $5 \mathrm{~min}$, the mixture was allowed to stand for $15 \mathrm{~min}$, and the aqueous phase was collected and precipitated with $80 \%$ ethanol. After filtration with a $0.22 \mu \mathrm{m}$ Millex-GP syringe filter unit (Merck Millipore; Burlington, MA, USA), the final product was lyophilized.

DeinoPol quantification. Total carbohydrates were estimated using the anthrone method as described previously ${ }^{21}$. Lyophilized DeinoPol was dissolved in $0.2 \mathrm{~mL}$ of distilled water and mixed with $0.8 \mathrm{~mL}$ of $0.2 \%$ anthrone solution in sulfuric acid. DeinoPol was hydrolyzed into simple sugars at $90^{\circ} \mathrm{C}$ for $10 \mathrm{~min}$ and cooled to room temperature. The optical density was then measured at $620 \mathrm{~nm}$ using a Victor X3 light plate reader (PerkinElmer, Waltham, MA, USA). D-glucose was used as a standard, and values are represented as percent of dry weight of the samples. The concentration of DNA and protein in purified DeinoPol was measured using the NanoVuePlus spectrophotometer (GE Healthcare; IL, USA).

Carbohydrate composition analysis. Monosaccharide analysis was performed using a CarboPac ${ }^{\mathrm{TM}}$ PA-10 column (guard column $4 \times 50 \mathrm{~mm}$ ) (Dionex, Sunnyvale, CA, USA) coupled to a Dionex DX500 series chromatograph (Dionex) at the Korea Basic Science Institute (Ochang, South Korea), as described previously ${ }^{47}$. In brief, DeinoPol $(10 \mathrm{mg})$ was dissolved in $0.5 \mathrm{M}$ trifluoroacetic acid $(5 \mathrm{~mL})$ and incubated for $24 \mathrm{~h}$ at $60^{\circ} \mathrm{C}$ followed by purification using Bio-Gel P-4 (200-400 mesh) (Bio-Rad, Hercules, CA, USA). The hydrolyzed monosaccharides were analyzed with Bio-LC high-performance chromatography. Data were processed using Thermo Scientific $^{\mathrm{TM}}$ Chromeleon $^{\mathrm{TM}}$ Data System software (Waltham, MA, USA).

Biofilm quantitative assay. Biofilm quantification was performed by crystal violet staining, as described previously ${ }^{48}$. Overnight cultures of $D$. radiodurans $\mathrm{R} 1$ and its isogenic mutant ( $\Delta$ dra0033) were diluted 1:100 in $2 \times$ TGY broth and transferred into flat-bottomed polystyrene 96 -well micro-titer plates (SPL, Pocheon, South Korea). After $48 \mathrm{~h}$ incubation at $30^{\circ} \mathrm{C}$, unattached bacteria were gently washed with $300 \mu \mathrm{L}$ phosphate buffer saline (PBS; Lonza, Basel, Switzerland) and stained with $0.2 \%$ crystal violet solution for $1 \mathrm{~min}$. Thereafter, excess crystal violet was removed by washing five times with $300 \mu \mathrm{L}$ PBS. Crystal violet was solubilized with $200 \mu \mathrm{L}$ acetone:ethanol $(2: 8 \mathrm{v} / \mathrm{v})$. Supernatants were transferred onto a new flat-bottomed 96-well plate, and the optical density was measured at $570 \mathrm{~nm}$ using a Victor X3 light plate reader (PerkinElmer, Waltham, MA, USA).

Scanning electron microscopy (SEM) analysis. Deinococcus radiodurans $\mathrm{R} 1$ and its isogenic mutant $(\Delta d r a 0033)$ were harvested at $\mathrm{A} 600=0.5$ and fixed overnight at $4{ }^{\circ} \mathrm{C}$ in $4 \%$ glutaraldehyde. After centrifugation, the pellet was washed three times with PBS and dehydrated through a graded ethanol series (35\%, 50\%, and 70\%), followed by drying the cells in a drying chamber. The samples were gold-coated using a gold sputtering unit and observed using a JEOL JSM-840 scanning electron microscope (Tokyo, Japan) at the Seoul National University. 
Deinococcal survival assay. Deinococcus radiodurans $\mathrm{R} 1$ and its isogenic mutant ( $\Delta$ dra0033) were cultured at $\log$ phase $(\mathrm{A} 600=1.0)$ and the number of cells was adjusted to approximately $10^{7} \mathrm{CFU} / \mathrm{mL}$ in TGY broth. To test the resistance to environmental stress, cells were treated with hydrogen peroxide (Sigma-Aldrich; St.Louis, MO, USA) for $60 \mathrm{~min}$ or irradiated with UV light $(302 \mathrm{~nm})$ from the CL-1000 irradiator (UVP; Upland, CA, USA) or $\gamma$-irradiated for $60 \mathrm{~min}$ using a ${ }^{60} \mathrm{Co}$-gamma irradiator (point source, AECL, IR-79; MDS Nordion International Co., Ltd.; Ontario, Canada) at the Advanced Radiation Technology Institute, Korea Atomic Energy Research Institute, with an absorbed dose of 5-15 kGy. For survival under desiccation, $10 \mu \mathrm{L}$ of bacteria-containing medium was placed on the glass slide (SPL) and then stored in a desiccation jar for 3 days, followed by washing the cells with $100 \mu \mathrm{L}$ PBS and spotting onto TGY agar plates serially.

Cell culture conditions. Primary human epidermal keratinocytes (NHEK-Ad) and an immortal human keratinocyte cell line (HaCaT) were obtained from Lonza and the Korean Cell Line Bank (Seoul, Korea). The cells were cultured in $\mathrm{KBM}^{\mathrm{TM}}-2$ medium (Lonza; Basel, Switzerland) with $\mathrm{KGM}^{\mathrm{TM}}-2$ growth supplement (Lonza), $100 \mathrm{U} / \mathrm{mL}$ penicillin and $100 \mu \mathrm{g} / \mathrm{mL}$ streptomycin (Gibco; Grand Island, NY, USA) at $37^{\circ} \mathrm{C}$ in a humidified chamber supplemented with $5 \% \mathrm{CO}_{2}$.

Cell proliferation assay. A Cell Counting Kit-8 (CCK-8: Dojindo; Kumamoto, Japan) was used to measure the cytotoxicity and proliferation of NHEK-Ad. Cells were plated at a density of $10^{4}$ cells per well in a 96 -well cell culture plate (SPL); $5 \mu \mathrm{L} \mathrm{CCK}-8$ was added to each well and incubated for an additional $2 \mathrm{~h}$ at $37^{\circ} \mathrm{C}$. Viable cells were estimated by measuring the optical density at $450 \mathrm{~nm}$ using a Victor X3 light plate reader (Perkin-Elmer).

Measurement of intracellular ROS. Human adult primary keratinocytes (NHEK-Ad, Lonza) were plated on black 96-well cell culture plates (SPL). When cells reached $70-80 \%$ confluence, $20 \mu \mathrm{L}$ DCFDA/ ${ }_{2}$ DCFDA (Abcam; Cambridge, UK) was pre-loaded to each well followed by UV exposure. The fluorescence intensity of each well was measured $30 \mathrm{~min}$ after irradiation with excitation $485 \mathrm{~nm}$ and emission $530 \mathrm{~nm}$, using a Victor X3 light plate reader (Perkin-Elmer) or observed immediately under a fluorescence microscope (Olympus; Tokyo, Japan).

In vitro wound healing assay. Human keratinocyte cell line ( $\mathrm{HaCaT})$ was seeded in a tissue culture 6-well plate at an initial density of $3 \times 10^{4}$ cells/well overnight. When cells reached $95 \%$ confluence, a micropipette tip was used to scratch a wound on the monolayer as described previously ${ }^{26}$. Wells were then treated with $\mathrm{H}_{2} \mathrm{O}_{2}$ and/or DeinoPol $(10 \mu \mathrm{g})$, and wound closure was observed by phase contrast microscopy (Nikon; Tokyo, Japan). Digital images were taken at $18 \mathrm{~h}$.

Western blotting analysis. NHEK-Ad cells $\left(10^{5}\right)$ were plated on 6 -well cell-culture plates (SPL). At $80 \%$ confluence, the wells were pre-treated with DeinoPol $(10 \mu \mathrm{g})$ followed by irradiation with $120 \mathrm{~mJ} / \mathrm{cm}^{2} \mathrm{UV}$ light. After $6 \mathrm{~h}$ of incubation at $37^{\circ} \mathrm{C}$, cells were lysed with RIPA buffer (Sigma-Aldrich) and separated on Bis-Tris Bolt gel (Invitrogen; Carlsbad, CA, USA) followed by transfer onto nitrocellulose membranes (Bio-Rad; Hercules, CA, USA). Membranes were blocked in 5\% skimmed dry milk (Bio-Rad) in 0.05\% Tween-20 in PBS (PBS-T) and then incubated with anti-Bcl-2 IgG1 monoclonal antibody (Santa Cruz Biotechnology; Santa Cruz, CA) or anti-Bax IgG2b monoclonal antibody (Santa Cruz Biotechnology). The membrane was then washed and incubated with horseradish peroxidase (HRP)-conjugated rabbit anti-mouse immunoglobulin (Southern Biotech; Birmingham, AL, USA). Membrane-bound peroxidase was detected by TMB-ELISA substrate solution (Thermo-Fisher; Waltham, MA, USA).

Caspase 3/7 activity assay. Caspase 3/7 activity was analyzed using a Caspase-3/7 fluorescence assay kit (Cayman Chemical; Ann Arbor, MI, USA) following the manufacturer's protocols. In brief, $10^{4}$ NHEK-Ad cells were plated into 96-well cell culture plates (SPL). At $80 \%$ confluence, the cells were irradiated with $120 \mathrm{~mJ} / \mathrm{cm}^{2}$ UV light with or without pre-treatment of DeinoPol $(10 \mu \mathrm{g})$. After $3 \mathrm{~h}$, cells were lysed, followed by incubation of $90 \mu \mathrm{L}$ cell lysate and $10 \mu \mathrm{L}$ caspase $3 / 7$ substrate solution. The fluorescence intensity of each well was measured with excitation $485 \mathrm{~nm}$ and emission $535 \mathrm{~nm}$ using a Victor X3 light plate reader (PerkinElmer).

Cell apoptosis analysis. NHEK-Ad cells $\left(10^{4}\right)$ were plated on 6 -well cell culture plates (SPL). At $80 \%$ confluence, the cells were irradiated with 10 Gy of $\gamma$-radiation using a Gammacell ${ }^{\circledR} 40$ Exactor (Best Theratronics; Ottawa, Canada) at the Advanced Radiation Technology Institute, Korea Atomic Energy Research Institute. Cells were trypsinized, washed, and stained with Dead Cell Apoptosis Kit with Annexin V-Alexa Fluor 488 and PI (BD Bioscience; San Jose, CA, USA) and incubated for $15 \mathrm{~min}$ at $37^{\circ} \mathrm{C}$ in the dark. Cells were analyzed by MACSQuant flow cytometry (Miltenyi Biotech; Bergisch Gladbach, Germany). TUNEL assay was also used to determine the effect of DeinoPol on radiation-induced cell apoptosis according to the manufacturer's instructions (Promega). In brief, cells were treated with cold $4 \%$ paraformaldehyde for 30 min and $0.3 \%$ Triton X-100 was added for $5 \mathrm{~min}$. The TUNEL detecting solution (terminal deoxynucleotidyl transferase and fluorescence solution) was added and allowed to stand for $60 \mathrm{~min}$ at $37^{\circ} \mathrm{C}$. Images were acquired using an Olympus IX3 inverted fluorescence microscope (Tokyo, Japan).

\section{Data availability}

The data sets generated and/or analyzed during the current study are available from the corresponding author on reasonable request.

Received: 2 August 2019; Accepted: 27 November 2019;

Published online: 09 January 2020 


\section{References}

1. Bickers, D. R. \& Athar, M. Oxidative stress in the pathogenesis of skin disease. J Invest Dermatol 126, 2565-2575, https://doi. org/10.1038/sj.jid.5700340 (2006).

2. Perluigi, M. et al. Effects of UVB-induced oxidative stress on protein expression and specific protein oxidation in normal human epithelial keratinocytes: a proteomic approach. Proteome Sci 8, 13, https://doi.org/10.1186/1477-5956-8-13 (2010).

3. Pillai, S., Oresajo, C. \& Hayward, J. Ultraviolet radiation and skin aging: roles of reactive oxygen species, inflammation and protease activation, and strategies for prevention of inflammation-induced matrix degradation - a review. Int J Cosmet Sci 27, 17-34, https:// doi.org/10.1111/j.1467-2494.2004.00241.x (2005).

4. Cadet, J. \& Davies, K. J. A. Oxidative DNA damage \& repair: An introduction. Free Radic Biol Med 107, 2-12, https://doi. org/10.1016/j.freeradbiomed.2017.03.030 (2017).

5. Farooqi, A. A. et al. Natural products mediated regulation of oxidative stress and DNA damage in ultraviolet exposed skin cells. Curr Pharm Biotechnol 16, 1078-1084 (2015).

6. Park, G., Sim, Y., Lee, W., Sung, S. H. \& Oh, M. S. Protection on skin aging mediated by antiapoptosis effects of the water lily (Nymphaea tetragona Georgi) via reactive oxygen species scavenging in human epidermal keratinocytes. Pharmacology 97, 282-293, https://doi.org/10.1159/000444022 (2016).

7. Sirerol, J. A. et al. Topical treatment with pterostilbene, a natural phytoalexin, effectively protects hairless mice against UVB radiation-induced skin damage and carcinogenesis. Free Radic Biol Med 85, 1-11, https://doi.org/10.1016/j.freeradbiomed. 2015.03.027 (2015)

8. Caggianiello, G., Kleerebezem, M. \& Spano, G. Exopolysaccharides produced by lactic acid bacteria: from health-promoting benefits to stress tolerance mechanisms. Applied Microbiol Biotechnol 100, 3877-3886, https://doi.org/10.1007/s00253-016-7471-2 (2016).

9. Nwodo, U. U., Green, E. \& Okoh, A. I. Bacterial exopolysaccharides: functionality and prospects. Int J Mol Sci 13, 14002-14015, https://doi.org/10.3390/ijms131114002 (2012).

10. Paulo, E. M. et al. Production, extraction and characterization of exopolysaccharides produced by the native Leuconostoc pseudomesenteroides R2 strain. An Acad Bras Cienc 84, 495-508 (2012).

11. Freitas, F., Alves, V. D. \& Reis, M. A. Advances in bacterial exopolysaccharides: from production to biotechnological applications. Trends in Biotechnology 29(8), 388-398 (2011).

12. Wolter, A. et al. Evaluation of exopolysaccharide producing Weissella cibaria MG1 strain for the production of sourdough from various flours. Food Microbiol 37, 44-50, https://doi.org/10.1016/j.fm.2013.06.009 (2014).

13. Yu, Y. J., Chen, Z., Chen, P. T. \& Ng, I. S. Production, characterization and antibacterial activity of exopolysaccharide from a newly isolated Weissella cibaria under sucrose effect. J Biosci Bioeng. https://doi.org/10.1016/j.jbiosc.2018.05.028 (2018).

14. Lim, S., Jung, J. H., Blanchard, L. \& de Groot, A. Conservation and diversity of radiation and oxidative stress resistance mechanisms in Deinococcus species. FEMS Microbiol Rev 43, 19-52, https://doi.org/10.1093/femsre/fuy037 (2019).

15. Daly, M. J. A new perspective on radiation resistance based on Deinococcus radiodurans. Nat Rev Microbiol 7, 237-245, https://doi. org/10.1038/nrmicro2073 (2009).

16. Basu, B. \& Apte, S. K. Gamma radiation-induced proteome of Deinococcus radiodurans primarily targets DNA repair and oxidative stress alleviation. Mol Cell Proteomics 11, M111 011734, https://doi.org/10.1074/mcp.M111.011734 (2012).

17. Farci, D. et al. New features of the cell wall of the radio-resistant bacterium Deinococcus radiodurans. Biochim Biophys Acta 1838, 1978-1984, https://doi.org/10.1016/j.bbamem.2014.02.014 (2014).

18. Huang, J. \& Schell, M. Molecular characterization of the eps gene cluster of Pseudomonas solanacearum and its transcriptional regulation at a single promoter. Mol Microbiol 16, 977-989 (1995).

19. Gruter, M., Leeflang, B. R., Kuiper, J., Kamerling, J. P. \& Vliegenthart, J. F. Structure of the exopolysaccharide produced by Lactococcus lactis subspecies cremoris H414 grown in a defined medium or skimmed milk. Carbohydr Res 231, 273-291 (1992).

20. Wan, H. Y. J., Shan, X., Wu, Q. \& Shi, N. Structure and bio-properties of extracellular polysaccharide from Bacillus sp. strain LBP32 isolated from LUOBOPO desert. Biotechnol Bioprocess Eng 16, 761-768 (2011).

21. Calix, J. J., Saad, J. S., Brady, A. M. \& Nahm, M. H. Structural characterization of Streptococcus pneumoniae serotype 9A capsule polysaccharide reveals role of glycosyl 6-O-acetyltransferase wcjE in serotype $9 \mathrm{~V}$ capsule biosynthesis and immunogenicity. J Biol Chem 287, 13996-14003, https://doi.org/10.1074/jbc.M112.346924 (2012).

22. Burdak-Rothkamm, S. \& Rothkamm, K. Radiation-induced bystander and systemic effects serve as a unifying model system for genotoxic stress responses. Mutation Res 778, 13-22, https://doi.org/10.1016/j.mrrev.2018.08.001 (2018).

23. Klaunig, J. E. Oxidative stress and cancer. Curr Pharm Des 24, 4771-4778, https://doi.org/10.2174/1381612825666190215121712 (2018).

24. Srinivas, U. S., Tan, B. W. Q., Vellayappan, B. A. \& Jeyasekharan, A. D. ROS and the DNA damage response in cancer. Redox Biol 101084, https://doi.org/10.1016/j.redox.2018.101084 (2018).

25. Watson, R. E., Gibbs, N. K., Griffiths, C. E. \& Sherratt, M. J. Damage to skin extracellular matrix induced by UV exposure. Antioxid Redox Signal 21, 1063-1077, https://doi.org/10.1089/ars.2013.5653 (2014).

26. Rodriguez, L. G., Wu, X. \& Guan, J. L. Wound-healing assay. Methods Mol Biol 294, 23-29 (2005).

27. Kerr, J. F. R., Wyllie, A. H. \& Currie, A. R. Apoptosis: A basic biological phenomenon with wide ranging implications in tissue kinetics. Br J Cancer 26, 239-257 (1972).

28. Rapoport, A. P. et al. Flavopiridol induces apoptosis and caspase-3 activation of a newly characterized Burkitt's lymphoma cell line containing mutant p53 genes. Blood Cells Mol Dis 27, 610-624 (2001).

29. Salakou, S. et al. Increased Bax/Bcl-2 ratio up-regulates caspase-3 and increases apoptosis in the thymus of patients with myasthenia gravis. In Vivo 21, 123-132 (2007).

30. Kehrer, J. P. The Haber-Weiss reaction and mechanisms of toxicity. Toxicology 149, 43-50 (2000).

31. Rigo, A., Stevanato, R., Finazzi-Agro, A. \& Rotilio, G. An attempt to evaluate the rate of the Haber-Weiss reaction by using OH radical scavengers. FEBS Lett 80, 130-132 (1977).

32. Luan, H. et al. Genome-wide transcriptome and antioxidant analyses on gamma-irradiated phases of Deinococcus radiodurans R1. PloS One 9, e85649, https://doi.org/10.1371/journal.pone.0085649 (2014).

33. Zhu, Y. et al. Purification, characterization and antioxidant activity of the exopolysaccharide from Weissella cibaria SJ14 isolated from Sichuan paocai. Int J Biol Macromol 115, 820-828, https://doi.org/10.1016/j.ijbiomac.2018.04.067 (2018).

34. Laure Jolly, Francesca Stingele. Molecular organization and functionality of exopolysaccharide gene clusters in lactic acid bacteria. International Dairy Journal 11(9), 733-745 (2001).

35. Misu Moscovici. Present and future medical applications of microbial exopolysaccharides. Frontiers in Microbiology 6 (2015).

36. Delattre, C., Pierre, G, Laroche, C. \& Michaud, P. Production, extraction and characterization of microalgal and cyanobacterial exopolysaccharides. Biotechnol Adv 34, 1159-1179, https://doi.org/10.1016/j.biotechadv.2016.08.001 (2016).

37. Lynch, K. M., Zannini, E., Coffey, A. \& Arendt, E. K. Lactic acid bacteria exopolysaccharides in foods and beverages: Isolation, properties, characterization, and health benefits. Annu Rev Food Sci Technol 9, 155-176, https://doi.org/10.1146/annurevfood-030117-012537 (2018)

38. Cruz, M., Freitas, F., Torres, C. A., Reis, M. A. \& Alves, V. D. Influence of temperature on the rheological behavior of a new fucosecontaining bacterial exopolysaccharide. Int J Biol Macromol 48, 695-699, https://doi.org/10.1016/j.ijbiomac.2011.02.012 (2011).

39. Kim, Y., Oh, S., Yun, H. S., Oh, S. \& Kim, S. H. Cell-bound exopolysaccharide from probiotic bacteria induces autophagic cell death of tumour cells. Lett Appl Microbiol 51, 123-130, https://doi.org/10.1111/j.1472-765X.2010.02859.x (2010). 
40. Poli, A. et al. Production and chemical characterization of an exopolysaccharide synthesized by psychrophilic yeast strain Sporobolomyces salmonicolor AL(1) isolated from Livingston Island, Antarctica. Folia Microbiol (Praha) 55, 576-581, https://doi. org/10.1007/s12223-010-0092-8 (2010).

41. Wang, X., Zhang, Y., Liu, Z., Zhao, M. \& Liu, P. Purification, characterization, and antioxidant activity of polysaccharides isolated from Cortex Periplocae. Molecules 22, https://doi.org/10.3390/molecules22111866 (2017).

42. Yin, Z., Zhang, W., Zhang, J. \& Kang, W. Isolation, purification, structural analysis and coagulatory activity of water-soluble polysaccharides from Ligustrum lucidum Ait flowers. Chem Cent J 11, 98, https://doi.org/10.1186/s13065-017-0332-y (2017).

43. Ayala-Hernandez, I., Goff, H. D. \& Corredig, M. Interactions between milk proteins and exopolysaccharides produced by Lactococcus lactis observed by scanning electron microscopy. J Dairy Sci 91, 2583-2590, https://doi.org/10.3168/jds.2007-0876 (2008).

44. Prendecka, M. et al. Effect of exopolysaccharide from Ganoderma applanatum on the electrical properties of mouse fibroblast cells line L929 culture using an electric cell-substrate impedance sensing (ECIS) - Preliminary study. Ann Agric Environ Med 23, 280-284, https://doi.org/10.5604/12321966.1203891 (2016).

45. Ryan, P. M., Ross, R. P., Fitzgerald, G. F., Caplice, N. M. \& Stanton, C. Sugar-coated: exopolysaccharide producing lactic acid bacteria for food and human health applications. Food Funct 6, 679-693, https://doi.org/10.1039/c4fo00529e (2015).

46. Appukuttan, D. et al. Expression and mutational analysis of DinB-like protein DR0053 in Deinococcus radiodurans. PloS One 10, e0118275, https://doi.org/10.1371/journal.pone.0118275 (2015).

47. Ha, Y. W., Son, M. J., Yun, K. S. \& Kim, Y. S. Relationship between eggshell strength and keratan sulfate of eggshell membranes. Comp Biochem Physiol A Mol Integr Physiol 147, 1109-1115, https://doi.org/10.1016/j.cbpa.2007.03.022 (2007).

48. Shukla, S. K. \& Rao, T. S. The first recorded incidence of Deinococcus radiodurans R1 biofilm formation and its implications in heavy metals bioremediation. 234781, https://doi.org/10.1101/234781\%J bioRxiv (2017)

\section{Acknowledgements}

This work was supported by the National Research Foundation of Korea (NRF-2018K2A206023828 and NRF2017M2A2A6A02020925 to HSS) and the Nuclear R\&D Program of the Ministry of Science and ICT to SL.

\section{Author contributions}

S.M.L., C.Y.B., S.L. and H.S.S. conceived the study. S.M.L., C.Y.B., S.L. and H.S.S. designed the experiments. S.M.L., C.Y.B., J.H.J., W.S.K., H.Y.S., J.H.L., H.J.J., Y.Z., and H.S.S. performed the experiments. S.M.L., C.Y.B., Y.S.B., S.L. and H.S.S. analyzed and/or interpreted the data and contributed to discussion of the results, followed by writing and reviewing the manuscript. B.S.K., Y.S.B., S.L. and H.S.S. provided critical comments and contributed to discussion of the results, followed by writing and reviewing the manuscript.

\section{Competing interests}

The authors declare no competing interests.

\section{Additional information}

Supplementary information is available for this paper at https://doi.org/10.1038/s41598-019-56141-3.

Correspondence and requests for materials should be addressed to H.S.S. or S.L.

Reprints and permissions information is available at www.nature.com/reprints.

Publisher's note Springer Nature remains neutral with regard to jurisdictional claims in published maps and institutional affiliations.

(c) (i) Open Access This article is licensed under a Creative Commons Attribution 4.0 International (c) License, which permits use, sharing, adaptation, distribution and reproduction in any medium or format, as long as you give appropriate credit to the original author(s) and the source, provide a link to the Creative Commons license, and indicate if changes were made. The images or other third party material in this article are included in the article's Creative Commons license, unless indicated otherwise in a credit line to the material. If material is not included in the article's Creative Commons license and your intended use is not permitted by statutory regulation or exceeds the permitted use, you will need to obtain permission directly from the copyright holder. To view a copy of this license, visit http://creativecommons.org/licenses/by/4.0/.

(c) The Author(s) 2020 